UDC 504:332.33:606(470.45)

LBC 20.18

\title{
REDUCTION OF THE NEGATIVE IMPACT ON AGROCENOSES BY MANAGING ADJACENT NATURAL AND ANTHROPOGENIC SYSTEMS ${ }^{1}$
}

\author{
Elena A. Ivantsova \\ Volgograd State University, Volgograd, Russian Federation \\ Nikolay V. Onistratenko \\ Volgograd State University, Volgograd, Russian Federation \\ Anna V. Kholodenko \\ Volgograd State University, Volgograd, Russian Federation \\ Anna A. Tikhonova \\ Volgograd State University, Volgograd, Russian Federation \\ Valeriy V. Novochadov \\ Volgograd State University, Volgograd, Russian Federation
}

Abstract. The use of modern eco-oriented approaches in agriculture ensures not only the conservation of natural resources and the restoration of damaged ecosystems, but also the growth of agrocenoses productivity, increasing the tolerance of artificial ecosystems to unfavorable factors of natural and anthropic origin. The identification of consortia relations, carried out in the present article, allows to create the information database for accumulating and processing information on the patterns of ecosystem functioning in arid conditions. This provides researchers and farmers with a set of unified ecosystem tools to ensure sustainability and productivity of agrocenosis that increases the economic efficiency of management system and ensures the success of environmental management.

The research carried out in three typical landscape localizations are intended to assess the state of agrocenoses, the nearby low-changed steppe sites and man-made intrusions, characterized by a high degree of anthropogenic load. The patterns of species distribution in the studied communities, the features of material and energy exchange will allow creating a database for describing the typical consortia, forecasting processes in agrocenoses and natural communities, controling the metabolism of the communities using metered-dose unidirectional biotic and abiotic agents. The distinctive natural and artificially modified communities are described. Soil and climate, phytocenological, zoological and microbiological characteristics of the studied objects are given. The peculiar forms of intrusions, the features of spatial distribution and quantitative dynamics of the species composing the communities are revealed and described; the typical species-edificators are pre-determined.

The authors also determine the choice of consortium relations that are significant for the implementation of targeted high-precision management of biocenoses with the aim of increasing the stability of natural communities and the economic efficiency of agrocenoses.

$\overbrace{}^{\top}$

Key words: agrocenoses, agricultural nature management, damaged ecosystems, consortia relations, management of biocenoses, database. 


\title{
СНИЖЕНИЕ НЕГАТИВНОГО ВОЗДЕЙСТВИЯ НА АГРОЦЕНОЗЫ ПУТЕМ УПРАВЛЕНИЯ ПРИМЫКАЮЩИМИ ПРИРОДНО-АНТРОПОГЕННЫМИ СИСТЕМАМИ ${ }^{1}$
}

\author{
Елена Анатольевна Иванцова \\ Волгоградский государственный университет, г. Волгоград, Российская Федерация \\ Николай Владимирович Онистратенко \\ Волгоградский государственный университет, г. Волгоград, Российская Федерация
}

Анна Викторовна Холоденко

Волгоградский государственный университет, г. Волгоград, Российская Федерация

\section{Анна Афанасьевна Тихонова}

Волгоградский государственный университет, г. Волгоград, Российская Федерация

\section{Валерий Валерьевич Новочадов}

Волгоградский государственный университет, г. Волгоград, Российская Федерация

Аннотация. Использование современных экологоориентированных подходов в сельском хозяйстве обеспечивает не только сохранение природных ресурсов и восстановление нарушенных экосистем, но и рост продуктивности агроценозов, повышение толерантности искусственных экосистем к неблагоприятным факторам естественного и антропического генеза. Выявление консортных связей, на которое направлена представленная работа, позволяет создать информационную базу для накопления и обработки сведений о закономерностях функционирования экосистем в аридных условиях, что обеспечивает исследователя и агрария набором унифицированных экосистемных инструментов для обеспечения баланса устойчивости и продуктивности агроценоза, что ведет к росту экономической эффективности системы хозяйствования и повышению успешности природопользования.

Осуществленные в трех типичных ландшафтных локализациях исследования имели целью оценить состояние агроценозов, близлежащих малоизмененных степных участков и техногенных интрузий, характеризующихся высокой степенью антропогенной нагрузки. Закономерности распределения видов живых организмов в исследуемых сообществах и особенности материально-энергетического обмена позволят в дальнейшем создать базу данных для описания типичных консорций, прогнозирования процессов в агроценозах и природных сообществах, управления метаболизмом сообществ посредством дозированного индивидуально направленного воздействия с помощью биотических и абиотических агентов. Были описаны характерные природные и искусственно измененные сообщества. Даны почвенно-климатическая, фитоценологическая, зоологическая и микробиологическая характеристики исследуемых объектов. Были выявлены и описаны характерные формы интрузий, определены особенности пространственного распределения и количественной динамики видов, слагающих сообщества, предварительно определены типичные виды-эдификаторы.

Обусловлен выбор консортных связей, значимых для осуществления адресного высокоточного управления биоценозами с целью повышения устойчивости природных сообществ и экономической эффективности агроценозов.

Ключевые слова: агроценозы, сельскохозяйственное природопользование, нарушенные экосистемы, консортные связи, управление биоценозами, база данных.

Логическим развитием биологизации сельского хозяйства становится экологический системный подход к управлению агроценозами. Современные сельскохозяйственные технологии предполагают активное вмешательство в структуру и функционирование агробиоценозов. Эффективность этого вмешательства определяется учетом естественных 
экологических механизмов, что подтверждает актуальность применения биотехнологий в сельском хозяйстве. Биотехнологии могут обеспечить направленное развитие биоценозов за счет привнесения биогенных компонентов (преимущественно бактерий или грибов) и воздействия на абиогенные факторы (акустические и оптические воздействия, химические модификаторы) на основе передовых достижений биофизики, молекулярной биологии, биологической химии и биоинженерии. Общие экологические закономерности переходят из разряда условий функционирования сельскохозяйственного производства в один из инновационных научно обоснованных инструментов $[1 ; 2 ; 3 ; 8 ; 9 ; 12 ; 13]$.

Для Юга России актуальной проблемой рационального природопользования остается обеспечение устойчивого функционирования агросистем в аридных условиях, что подтверждается сельскохозяйственной специализацией Волгоградской области и прилегающих субъектов РФ. Поскольку в составе агросистем встречаются как полностью искусственные, так и биоценозы с различной степенью антропогенной измененности, необходим адаптированный подход к регулированию их эффективности с акцентом на регулирование биоценотических связей в наземных экосистемах.

Зависимость материально-энергетической динамики биоценоза от влияния почвенных и климатических условий, а также особенности влияния аридности на состояние естественных и искусственных экосистем рассмотрены российскими и зарубежными исследователями. Аридность воспринимается элементами биоценоза как стрессовый фактор и вызывает специфические реакции $[3 ; 4 ; 10 ; 11]$. Однако пока еще недостаточно актуальных результатов детализированных исследований по данной тематике, учитывающих природно-климатическую специфику Нижнего Поволжья.

Специфическим явлением, осложняющим условия ведения сельского хозяйства в зоне рискового земледелия, к которой принадлежит и исследуемый регион, является устойчивое пространственное сочетание «агроценоз техногенная интрузия - степной участок». Причина в том, что земли, активно задействованные в аграрном производстве, закономерно расположены вблизи населенных пунктов и вовлечены в прочую хозяйственную деятельность человека. Видоизмененный фитоценоз, ставший регулярным агроценозом, испытывает усиленную антропогенную нагрузку, обусловленную влиянием физического воздействия, химического и биологического загрязнения, характерных для производства, хозяйственно-бытовой деятельности, транспортной составляющей. Особой спецификой обладают газо- и нефтетранспортные системы, реализованные в виде трубопроводов и сопутствующей инфраструктуры. Вторжение их в агроценозы создает нарушения второго порядка, поддерживаемые ввиду специфики прокладки, использования и обеспечения контроля и безопасности данных систем [6; 14].

Основным районом исследования была выбрана Волгоградская область с учетом зональных почвенно-климатических условий, которые соотносятся с северной границей аридной зоны на юго-востоке Европейской части России. Распространение аридной зоны на территории Волгоградской области соотносится с ее южными и юго-восточными районами и определяется принадлежностью к подзоне светло-каштановых почв в комплекce c солонцами. Большая часть территории Волгоградской области относится к зоне рискованного земледелия.

На территории региона в качестве объектов исследования были выбраны участки южной сухой степи и расположенные в их пределах сельскохозяйственные объекты - поля. Выбранные участки характеризуются сходным физико-географическим положением, ландшафтными особенностями, геоморфологическими, почвенными, гидрологическими и климатическими свойствами.

Участок № 1 расположен на территории Городищенского муниципального района Волгоградской области вдоль федеральной трассы Р-22 (Е-119) «Каспий» с северо-восточной стороны на границе с прилегающей к трассе аллеей Ракутина. Участок № 2 расположен на территории Советского района городского округа г. Волгоград к югу от поселка им. Гули Королевой и к западу от поселка Горнополянский, вблизи пересечения объездной и грунтовой дорог. Участок № 3 расположен на территории Светлоярского муниципального района Волгоградской области к юго-востоку от 
рабочего поселка Светлый Яр вдоль федеральной трассы Р-22 (Е-119) «Каспий» с южной стороны.

Во всех случаях при выборе участка акцент был сделан на пространственное сочетание агробиоценоза и элементов техногенного воздействия, наиболее характерных для района исследования (ЛЭП, подземные коммуникации, связанные с нефте- и газотранспортными системами, зоны прохода сельхозтехники).

В процессе исследования на территории каждого из участков на основе оценки степени антропогенного воздействия выделялись три ключевые зоны:

- зона агроценоза, являющаяся полностью искусственной экосистемой сельскохозяйственного назначения;

- зона техногенной интрузии, под которой понимается биогеоценоз, возникший в результате взаимодействия искусственной и квазиестественной экосистем, располагающихся на территории, включающей элементы техногенного воздействия;

- степная зона, находящаяся в квазиестественном состоянии.

С учетом характера антропогенного воздействия в зоне агроценоза техногенные интрузии в регионе исследования имеют различные варианты форм и ареалов. Наиболее часто встречающимися, по результатам натурных наблюдений, были признаны островные, вторгающиеся и пограничные (см. рисунок).

Воздействие интрузии на агроценоз имеет косвенный, преимущественно негативный характер и выражается в следующем:

Снижение негативного воздействия на агроценозы

- на периферии интрузии агроценоз демонстрирует снижение проективного покрытия и, как следствие, снижение биопродуктивности возделываемой культуры, что определяет урожайность как один из экономических показателей;

- зона интрузии усиливает техногенную миграцию элементов, что определяет качество сельскохозяйственной продукции;

- техногенная интрузия зачастую связана с формированием особого микрорельефа сельхозугодий, что влияет на условия поверхностного и подземного стока, меняет условия увлажнения и усиливает геохимический перенос поллютантов с последующим накоплением их в подсистеме агроценоза «почва-растение»;

- зона интрузии оказывает корректирующее воздействие на трофическую структуру и связи в прилегающем агроценозе и может иметь как положительные (усиление роли энтомофагов и опылителей в составе энтомокомплекса, создание рефугиума для микробиоты, зоологической и флористической составляющей сообщества), так и отрицательные (трансгрессия химических поллютантов и биогенных загрязнителей в сообщество, создание микросообществ, устойчивых к агрохимическим средствам борьбы) проявления.

Управление биогеоценозами в целом строится на оценке консортных связей между их основными структурными элементами: экотопом и биоценозом.

С учетом особенностей аридной зоны не все консортные связи между элементами био-

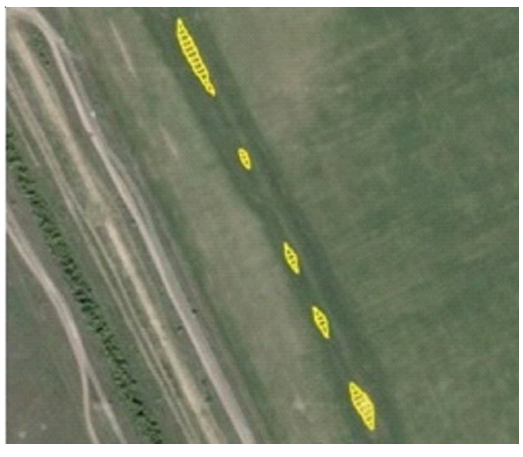

a

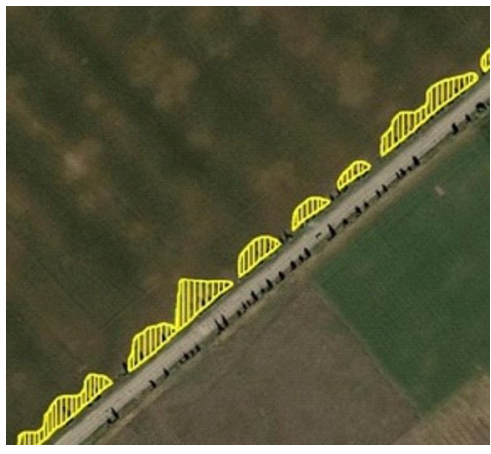

б

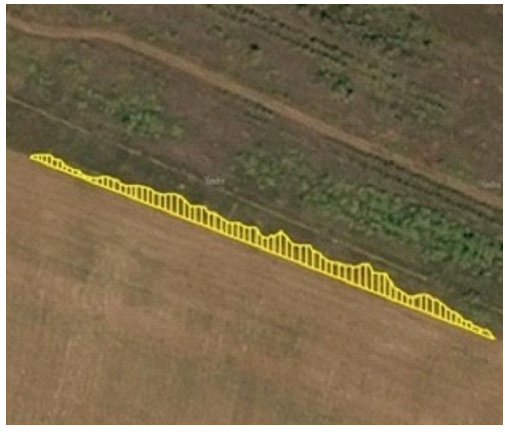

B

Рисунок. Выявленные варианты ареалов техногенных интрузий:

$a$ - островная; $\sigma$ - вторгающаяся; в - пограничная

Примечание. Составлено авторами по результатам исследовательских данных. 


\section{ЭкоЛОГИя}

геоценоза можно считать эффективными с точки зрения их управляющей функции. Так, к группе неуправляемых в этой зоне относятся обусловленные климатическими характеристиками температура воздуха и режим увлажнения почвы. Связи между остальными участниками можно проранжировать с точки зрения их устойчивости и интенсивности (табл. 1).

В таблице представлена интенсивность проявления связей, определяемая последовательно между элементами биогеоценоза (почва, растения, энтомокомплекс, микробиота), без учета характера последствий (положительных либо отрицательных).

Анализ приведенных консортных связей показывает, что наиболее значимыми с точки зрения управляющего воздействия среди них являются следующие: «почва - растение», «растения - энтомокомплекс», «микробиота почва». Для некоторых участников интенсивность связи варьирует в зависимости от направления. Это характерно для подсистем «почва - растения» и «микробиота - почва».

Таким образом, моделирование объектов управления при регулировании воздействия на агроценоз прилегающих ПАС в аридной зоне может быть основано на анализе сгенерированной в реляционной базе данных информации, которая будет сочетать в себе сведения об элементах биоценоза в зонах техногенных интрузий, степных участков в квазиестественном состоянии и агроценозов.
При этом эффективность управляемого воздействия должна определяться экологобиологической возможностью и экономической эффективностью и целесообразностью его реализации. Анализ возможности использования конкретных консортных связей для снижения негативных антропогенных воздействий на агроценоз применительно к району исследования представлен в таблице 2 в виде оценки значимости каждого типа связи в баллах от 0 до 3 (где 0 - отсутствие эффекта, а 3 - высокая эффективность).

С учетом развития современной техники и технологии эффективность применения биоэкологических механизмов воздействия на биоценозы определяется адресным характером разрабатываемых подходов и реализуемых мероприятий. При этом адресный подход предполагает точечное воздействие на наиболее управляемый (реактивный) компонент конкретного биоценоза.

Для разработки системы управления агробиоценозом с применением адресного подхода необходимо создание унифицированной базы данных, содержащей информацию об особенностях взаимодействия элементов естественных, антропогенных биоценозов и жестко управляемых агроэкосистем. Использование такой базы данных обеспечит снижение недифференцированного химического прессинга, позволит реализовывать индивидуальный подход к управлению биотическими

Таблица 1

Степень взаимного влияния элементов биогеоценоза

\begin{tabular}{|l|c|c|c|c|}
\hline \multirow{2}{*}{$\begin{array}{c}\text { Элемент биоценоза, } \\
\text { оказывающий } \\
\text { воздействие }\end{array}$} & \multicolumn{3}{|c|}{ Элемент биоценоза, испытывающий воздействие } \\
\cline { 2 - 5 } & Почва & Растения & Энтомокомплекс & Микробиота \\
\hline Почва & - & ++ & + & + \\
\hline Растения & ++ & ++ & +++ & ++ \\
\hline Энтомокомплекс & - & +++ & ++ & $-/+$ \\
\hline Микробиота & +++ & ++ & $-/+$ & ++ \\
\hline
\end{tabular}

Примечание. Составлено авторами.

Эколого-экономическая эффективность воздействия,

Таблииа 2 основанного на связи элементов биогеоценоза, в баллах

\begin{tabular}{|l|c|c|}
\hline \multicolumn{1}{|c|}{ Тип консортной связи } & $\begin{array}{c}\text { Эколого-биологическая } \\
\text { возможность реализации }\end{array}$ & $\begin{array}{c}\text { Технико-экономическая } \\
\text { эффективность }\end{array}$ \\
\hline Почва - растения & 3 & 2 \\
\hline Растения - энтомокомплекс & 2 & 1 \\
\hline Микробиота - почва & 2 & 1 \\
\hline
\end{tabular}

Примечание. Составлено авторами. 
взаимодействиями в сообществе посредством модулирования физических, химических и биотических факторов [5; 6; 7; 13; 15-17].

Анализ консортных связей является эффективным источником информации для выбора оптимального управляемого компонента. Для удобного хранения, систематизации и обработки первичной информации целесообразно создание и наполнение информационной базы данных (далее - БД) регионального уровня. Перспективы ее использования связаны с возможностями моделирования и прогнозирования управляющих воздействий при принятии решений и разработке мероприятий по управлению природно-антропогенными системами. таблице 3 .

Функциональная структура БД указана в

Структура БД предполагает выделение трех крупных блоков, соединенных между собой системными и логическими связями. Данные, содержащиеся в базе, иерархически организованы от первичной до аналитической информации, применимой для принятия управленческих решений.

Таким образом, одним из перспективных направлений повышения эколого-экономической эффективности агроценозов, расположенных в аридной зоне, является реализация адресного воздействия на управляемые компоненты биоценоза. Формирование алгоритма и характера предполагаемого воздействия с заданным эффектом может быть реализовано с помощью предварительного виртуального прогнозирования намечаемых воздействий на основе реляционной базы данных.

\section{ПРИМЕЧАНИЕ}

${ }^{1}$ Публикация подготовлена при финансовой поддержке Государственного задания Минобрнауки РФ по теме «Разработка экологоориентированных биотехнологий оптимизации аридных агробиоценозов Юга России на основе достижений физико-химической биологии и биоинформатики» (проект № 40.7534.2017/8.9).

\section{СПИСОК ЛИТЕРАТУРЫ}

1. Дудченко, Л. В. Эффективный биологический способ подавления сорных растений в полезащитных лесных насаждениях / Л. В. Дудченко // Достижения науки и техники АПК. - 2012. - № 7. C. 37-38.

2. Зубков, А. Ф. Агробиоценологическая модернизация защиты растений / А. Ф. Зубков. - СПб : ВИЗР, 2014. - 116 с. - (Приложения к журналу «Вестник защиты растений», №12).

3. Мушаева, К. Б. Оценка современного состояния агропастбищных ландшафтов полупустынной зоны республики Калмыкия с применением ГИС-технологий / К. Б. Мушаева // Вестник Волгоградского государственного университета. Серия 11 , Естественные науки. - 2015. - № 1. - С. 103-110.

4. Трифонова, Т. А. Моделирование стационарных состояний системы фитоценоз-почва

\section{Примерная схема строения базы данных элементов биогеоценоза}

\begin{tabular}{|c|c|c|c|}
\hline $\begin{array}{c}\text { Наименование } \\
\text { блока } \\
\text { в структуре БД }\end{array}$ & Блок 1. Элементы биогеоценоза & Блок 2. Консортные связи & $\begin{array}{c}\text { Блоки 3. Тип биогеоценоза } \\
\text { (агроценоз, интрузия, } \\
\text { степной участок) }\end{array}$ \\
\hline $\begin{array}{l}\text { Содержание } \\
\text { блока }\end{array}$ & $\begin{array}{l}\text { Фактический материал об } \\
\text { элементах биогеоценоза, } \\
\text { включая почвенно-экологи- } \\
\text { ческие особенности, фитоце- } \\
\text { нотические характеристики, } \\
\text { сложившийся энтомоком- } \\
\text { плекс, микробиоту }\end{array}$ & $\begin{array}{l}\text { Связи между основными эле- } \\
\text { ментами биогеоценоза («фито- } \\
\text { ценоз - вид-эдификатор», } \\
\text { «почва - фитоценоз», «виды- } \\
\text { эдификаторы - энтомоком- } \\
\text { плекс (фитофаги/энтомофаги)», } \\
\text { «фитоценоз - микрофлора } \\
\text { (фитопатогены/симбионты)», } \\
\text { «почва - типичные представи- } \\
\text { тели микробиоты» и др.) }\end{array}$ & $\begin{array}{l}\text { Пространственные характери- } \\
\text { стики отдельных биогеоцено- } \\
\text { зов и устойчивых пространст- } \\
\text { венных сочетаний «агроценоз- } \\
\text { интрузия-квазистепь» }\end{array}$ \\
\hline $\begin{array}{l}\text { Характер } \\
\text { информации }\end{array}$ & $\begin{array}{l}\text { Качественные и количествен- } \\
\text { ные данные }\end{array}$ & $\begin{array}{l}\text { Качественные и аналитиче- } \\
\text { ские данные }\end{array}$ & $\begin{array}{l}\text { Аналитические и управляю- } \\
\text { щие данные }\end{array}$ \\
\hline $\begin{array}{l}\text { Функциональная } \\
\text { роль в структуре } \\
\text { БД }\end{array}$ & $\begin{array}{l}\text { Накопление первичных дан- } \\
\text { ных для блока } 2\end{array}$ & $\begin{array}{l}\text { Установление консортных } \\
\text { связейна основе данных бло- } \\
\text { ка } 1 \text { (характер, направлен- } \\
\text { ность, интенсивность) }\end{array}$ & $\begin{array}{l}\text { Соотнесение информации в } \\
\text { составе блоков } 1 \text { и } 2 \text { с кон- } \\
\text { кретным биогеоценозом }\end{array}$ \\
\hline
\end{tabular}

Примечание. Составлено авторами. 
(на примере бассейна р. Клязьма) / Т. А. Трифонова, Л. А. Ширкин, Н. В. Мищенко// Почвоведение. 2012. -№ 8. - C. 889.

5. Шабаев, А. И. Адаптивно-экологический вектор развития ландшафтного земледелия на юговостоке Европейской части России / А. И. Шабаев // Аграрный вестник Юго-Востока. -2009. -№ 1 (1). C. 41-44.

6. A functional trait perspective on plant invasion / R. E. Drenovsky [et al.] // Annals of Botany. 2012. - № 110 (1). - P. 141-153.

7. Biochemical and Molecular Mechanisms of Plant-Microbe-Metal Interactions: Relevance for Phytoremediation / Y. Ma, R. S. Oliveira, H. Freitas, C. Zhang // Front Plant Sci. - 2016. - № 7. - P. 918.

8. Biotic and abiotic drivers of intraspecific trait variation within plant populations of three herbaceous plant species along a latitudinal gradient / K. Helsen, [et al.] // BMC Ecol. -2017. - № 17. - P. 38.

9. Invasive plants rapidly reshape soil properties in a grassland ecosystem / S. M. Gibbons [et al.] // mSystems. - 2017. - Vol. 2, № 2. - DOI: https:// doi.org/10.1128/mSystems.00178-16.

10. In vitro antagonistic activity, plantgrowth promoting traits and phylogenetic affiliation of rhizobacteria associated with wild plants grown in arid soil / W. S. El-Sayed, A. Akhkha, M. Y. ElNaggar, M. Elbadry // Front. Microbiol. - 2014. № 5. - P. 651 .

11. Leaf nitrogen and phosphorus of temperate desert plants in response to climate and soil nutrient availability / M. He [et al.] // Scientific Reports. 2014. - № 4.- - 6932.

12. Phylogenetic plant community structure along elevation is lineage specific / C. Ndiribe [et al.] // Ecology and Evolution. - 2013. - Vol. 3, № 15. P. 4925-4939.

13. Plant communities in harsh sites are less invaded: a summary of observations and proposed explanations/ E. Zefferman [etal.] // AoBPlants. -2015. № 7.-DOI: https://doi.org/10.1093/aobpla/plv056.

14. Synergistic effects of the components of global change: Increased vegetation dynamics in open, forest-steppe grasslands driven by wildfires and year-to-year precipitation differences / M. Kertész, R. Aszalós, A. Lengyel, G. Ónodi // PLoS One. - 2017. - Vol. 12, № 11. - DOI: https://doi.org/ 10.1371/journal.pone.0188260.

15. Tillage and nitrogen fertilization enhanced belowground carbon allocation and plant nitrogen uptake in a semi-arid canola crop-soil system / J. R. Sarker [et al.] // Scientific Reports. -2017. - № 7. -P. 10726.

16. The database of the PREDICTS projecting responses of ecological diversity in changing terrestrial systems project / L. N. Hudson [et al.] // Ecology and Evolution. -2017. -Vol. 7, № 1. - P. 145-188.
17. Understanding the development of roots exposed to contaminants and the potential of plantassociated bacteria for optimization of growth / T. Remans [et al.] // Annals of Botany. - 2012. Vol. 110, № 2. - P. 239-252.

\section{REFERENCES}

1. Dudchenko L.V. Effektivnyy biologicheskiy sposob podavleniya sornykh rasteniy $\mathrm{V}$ polezashchitnykh lesnykh nasazhdeniyakh [The Effective Biological Way of Suppressing the Weed Plants under Forest Belts]. Dostizheniya nauki $i$ tekhniki APK [Achievements Science and Technology of AIC], 2012, no. 7, pp. 37-38.

2. Zubkov A.F. Agrobiotsenologicheskaya modernizatsiya zashchity rasteniy [Agrobiocenological Modernization of Plant Protection]. Saint Petersburg, VIZR, 2014. 116p.

3. Mushaeva K.B. Otsenka sovremennogo sostoyaniya agropastbishchnykh landshaftov polupustynnoy zony respubliki Kalmykiya s primeneniem GIS-tekhnologiy [Assessment of the Current State of Agropastoral Landscapes in SemiArid Areas of the Kalmykia Republic with Application of GIS-technologies]. Vestnik Volgogradskogo gosudarstvennogo universiteta. Seriya 11. Estestvennye nauki [Science Journal of Volgograd State University. Natural Sciences], 2015, no. 1, pp. 103-110.

4. Trifonova T.A., Shirkin L.A., Mishchenko N.V. Modelirovanie statsionarnykh sostoyaniy sistemy fitotsenoz-pochva (na primere basseyna r. Klyazma) [Simulation of Stationary States of a PhytocenosisSoil System (the Case of the Klyazma River Basin]. Pochvovedenie, 2012, no. 8, pp. 793-801.

5. Shabaev A.I. Adaptivno-ekologicheskiy vektor razvitiya landshaftnogo zemledeliya na yugovostoke evropeyskoy chasti Rossii [Adaptive and Ecological Vector of Landscape Agriculture Development in the South-East European Part of Russia]. Agrarnyy vestnik Yugo-Vostoka, 2009, no. 1 (1), pp. 41-44.

6. Drenovsky R.E., Grewell B.J., D’Antonio C.M., Funk J.L., James J.J., Molinari N., et al. A functional trait perspective on plant invasion. Ann. Bot., 2012, vol. 110, no. 1, pp. 141-153.

7. Ma Y., Oliveira R.S., Freitas H., Zhang C. Biochemical and molecular mechanisms of plant-microbemetal interactions: relevance for phytoremediation. Front Plant Sci., 2016, no. 7, e918. DOI: https://doi.org/ 10.3389/fpls.2016.00918.

8. Helsen K., Acharya K.P., Brunet J., Cousins S.A.O., Decocq G., Hermy M., et al. Biotic and abiotic drivers of intraspecific trait variation within plant populations 
of three herbaceous plant species along a latitudinal gradient. BMC Ecol., 2017, no. 17, p. 38. DOI: https:// doi.org/10.1186/s12898-017-0151-y.

9. Gibbons S. M., Lekberg Y., Mummey D.L., Sangwan N., Ramsey P.W, Gilbert J.A. Invasive plants rapidly reshape soil properties in a grassland ecosystem. mSystems, 2017, vol. 2, no. 2, pp. e0017816. DOI: https://doi.org/10.1128/mSystems.00178-16.

10. El-Sayed W.S., Akhkha A., El-Naggar M.Y., Elbadry M. In vitro antagonistic activity, plant growth promoting traits and phylogenetic affiliation of rhizobacteria associated with wild plants grown in arid soil. Front. Microbiol., 2014, no. 5, p. 651. DOI: https://doi.org/10.3389/fmicb.2014.00651.

11. He M., Dijkstra F.A., Zhang K., Li X., Tan H., Gao Y., et al. Leaf nitrogen and phosphorus of temperate desert plants in response to climate and soil nutrient availability. Sci. Rep., 2014, no. 4, e6932. DOI: https://doi.org/10.1038/srep06932.

12. Ndiribe C., Pellissier L., Antonelli S., Dubuis A., Pottier J., Vittoz P., et al. Phylogenetic plant community structure along elevation is lineage specific. Ecol. Evol. 2013, vol. 3, no. 15, pp. 4925-4939.

13. Zefferman E., Stevens J.T., Charles G.K., Dunbar-Irwin M., Emam T., Fick S., et al. Plant communities in harsh sites are less invaded: a summary of observations and proposed explanations. $A o B$. Plants. 2015, no. 7, plv056. DOI: https://doi.org/10.1093/ aobpla/plv056.

14. Kertész M., Aszalós R., Lengyel A., Ónodi G. Synergistic effects of the components of global change: Increased vegetation dynamics in open, forest-steppe grasslands driven by wildfires and year-to-year precipitation differences. PLoSOne., 2017, vol. 12, no. 11, pp. e0188260. DOI: https://doi.org/10.1371/journal.pone.0188260.

15. Sarker J.R., Singh B.P., He X., Fang Y., Li G.D., Collins D. et al. Tillage and nitrogen fertilization enhanced belowground carbon allocation and plantnitrogen uptake in a semi-arid canola crop-soil system. Sci. Rep. 2017, no. 7, e10726. DOI: https:// doi.org/10.1038/s41598-017-11190-4.

16. Hudson L.N., Newbold T., Contu S., Hill S.L.L., Lysenko I., De Palma A., et al. The database of the PREDICTS (Projecting responses of ecological diversity in changing terrestrial systems) project. Ecol. Evol., 2017, vol. 7, no. 1, pp. 145-188.

17. Remans T., Thijs S., Truyens S., Weyens N., Schellingen K., Keunen E., et al. Understanding the development of roots exposed to contaminants and the potential of plant-associated bacteria for optimization of growth. Ann. Bot., 2012, vol. 110, no. 2, pp. 239-252.

\section{Information about the Authors}

Elena A. Ivantsova, Doctor of Sciences (Agriculture), Associate Professor, Head of Department of Ecology and Nature Management, Volgograd State University, Prosp. Universitetsky, 100, 400062 Volgograd, Russian Federation, Ivantsova@volsu.ru.

Nikolay V. Onistratenko, Candidate of Sciences (Biology), Associate Professor, Department of Ecology and Nature Management, Volgograd State University, Prosp. Universitetsky, 100, 400062 Volgograd, Russian Federation, Onistratenko@volsu.ru.

Anna V. Kholodenko, Candidate of Sciences (Geography), Associate Professor, Department of Ecology and Nature Management, Volgograd State University, Prosp. Universitetsky, 100, 400062 Volgograd, Russian Federation, Kholodenko@volsu.ru.

Anna A. Tikhonova, Postgraduate Student, Department of Ecology and Nature Management, Volgograd State University, Prosp. Universitetsky, 100, 400062 Volgograd, Russian Federation, tihonova@volsu.ru.

Valeriy V. Novochadov, Doctor of Sciences (Medicine), Professor, Director of the Institute of Natural Sciences, Volgograd State University, Prosp. Universitetsky, 100, 400062 Volgograd, Russian Federation, novochadov.valeriy@volsu.ru.

\section{Информация об авторах}

Елена Анатольевна Иванцова, доктор сельскохозяйственных наук, доцент, заведующая кафедрой экологии и природопользования, Волгоградский государственный университет, просп. Университетский, 100, 400062 г. Волгоград, Российская Федерация, Ivantsova@volsu.ru.

Николай Владимирович Онистратенко, кандидат биологических наук, доцент кафедры экологии и природопользования, Волгоградский государственный университет, просп. Университетский, 100, 400062 г. Волгоград, Российская Федерация, Onistratenko@volsu.ru. 
Анна Викторовна Холоденко, кандидат географических наук, доцент кафедры экологии и природопользования, Волгоградский государственный университет, просп. Университетский, 100, 400062 г. Волгоград, Российская Федерация, Kholodenko@volsu.ru.

Анна Афанасьевна Тихонова, аспирантка кафедры экологии и природопользования, Волгоградский государственный университет, просп. Университетский, 100, 400062 г. Волгоград, Российская Федерация, tihonova@volsu.ru.

Валерий Валерьевич Новочадов, доктор медицинских наук, профессор, директор института естественных наук, Волгоградский государственный университет, просп. Университетский, 100, 400062 г. Волгоград, Российская Федерация, novochadov.valeriy@volsu.ru. 